\title{
Correction to: Impact of leaf infestation by herbivorous insects on the elemental uptake of citrus trees
}

\author{
Khadija Semhi $^{1} \cdot$ Norbert Clauer $^{2} \cdot$ Ali Ahmed Al-Raeesi $^{1}$
}

Published online: 5 December 2018

(c) Deutsche Phytomedizinische Gesellschaft 2018

\section{Correction to: Journal of Plant Diseases and Protection https://doi.org/10.1007/s41348-018-0192-2}

In the original publication, the article title was incorrectly published as 'Impact of leave infestation by herbivorous insects on the elemental uptake of citrus trees'. The article title should read 'Impact of leaf infestation by herbivorous insects on the elemental uptake of citrus trees'.

The original article has been corrected.

The original article can be found online at https://doi.org/10.1007/ s41348-018-0192-2.

Norbert Clauer

nclauer@unistra.fr

1 Sultan Qaboos University, P.O. Box 36, Al-Khod 123, Muscat, Oman

2 Institut de Physique du Globe de Strasbourg (UdS-CNRS), 1 Rue Blessig, 67084 Strasbourg, France 